\title{
Adolescent Trauma and Psychosocial Wellbeing in Entebbe-Uganda
}

\author{
Ankwasiize Evarist \\ Dean Faculty of Social sciences and Psychology, University of Kisubi, Uganda
}

Copyright $\bigcirc 2018$ by authors, all rights reserved. Authors agree that this article remains permanently open access under the terms of the Creative Commons Attribution License 4.0 International License

\begin{abstract}
The general objective of the study was to explore adolescent trauma and its effects on psychosocial wellbeing of adolescents so as to initiate an adolescent trauma intervention model relevant in Uganda. The research objectives were based on nature and effects of trauma, effects of trauma on psychosocial wellbeing of adolescents and the perceived relationship between trauma and adolescents psychosocial wellness. The researcher used exploratory case study design with 86 respondents obtained by simple random and purposive sampling techniques. The likert scale standardized questionnaire "The child and adolescent trauma screen (CATS)" was administered to adolescent in relation to objective one and objective two. In order to obtain more classified information regarding the study of the objective three, the study used focus group discussion and this was carried out with the parents, teachers and counselors/ social workers to collect data. The researcher used coding sheets and descriptive analysis (bar charts, pie charts and frequency tables). The study concluded that adolescent trauma is caused by multiple factors including physical causes with more males at $66 \%$, as compared to females $54 \%$, sexually related causes with $7(70 \%)$ females and $3(30 \%)$ males, being touched indecently at $58.8 \%$ females and $46.1 \%$ males, and trauma related with poverty with highest source of trauma at $27 \%$ followed by fear of failure especially failure to succeed in their studies at $26 \%$. The study further revealed that trauma among adolescent affects them emotionally, academically and somatically manifested through bad feelings about one's body with $44 \%$ males and $56 \%$ of respondents being females leading to sleep related problems manifested more in males with $67.6 \%$ and less in females with $32.4 \%$. The study thus concludes that there is a need for multiple psychosocial interventions for adolescents in form of talk and expressive therapies. The study recommended that parents, counselors or social workers and teachers need on job training on addressing psychosocial needs of adolescents at school, health centers and in families.
\end{abstract}

Keywords Adolescent Trauma, Psychosocial
Wellbeing

\section{Introduction}

Globally, an estimated 71,000 adolescents make suicide attempts, brought about by untreated and unresolved presence of mental disorders such as trauma and Post Traumatic Stress Disorder (PTSD). World Health Organization (WHO) [1] emphasizes that adolescent mental health has neglected globally addressing issues of trauma and Post Traumatic Stress Disorders (PTSD). Kieling et al., [2] LR Anuradha et al., [3] argued that $10-20 \%$ of children and adolescents are affected with mental health problems and trauma is an issue especially in low-income and middle-income countries (Kim \&Taub, [4], supported by researches that out that the largest population is represented by adolescent globally, and are affected with mental health problems such as trauma and PTSD beginning in adolescence stage (Hawkins, S., Radcliffe, J.)[5].

Vittoria Ardino, [6] asserted that trauma changes the adolescent's brain neural proliferation and causes physiological alterations in the brain structure and functions of the key neural networks related to responses affiliated with stress leading to psychosocial unwellness in all dimension of adolescent's life.

A large epidemiological survey in the United States (US) found a life time prevalence rate for PTSD of $4.7 \%$ among adolescents. The incarcerated male adolescents often have a history of trauma, including chronic victimization along with an intergenerational experience of violence. Dhara Thakar, [7] argued that $77.5 \%$ of Southeast Asian American adolescents have witnessed physical aggression and community violence and $43.7 \%$ have been victims during their life time.

WHO discussed that the high rates of disease, including HIV/AIDS, cholera, tuberculosis, and malaria, being widely spread in Sub-Saharan Africa and play a distinct 
role in the types of trauma suffered by citizens of this region. WHO based on citizens in Sub-Saharan Africa yet this research is focusing on adolescent trauma. Young women and adolescents are affected by traumatic effects of gender-based violence Melissa A. et al. [8]. This affects adolescent's environment mastering in terms of social interaction and identity formation.

Sida, [9] spelt out that adolescents living on the streets are a consequence of the unimaginable trauma and poverty that the high number of African adolescents experience, this assertion is supported by the discoveries of Mandrup, L. \& Ask, E [10], who discovered in their study $80 \%$ of adolescents had been directly or indirectly exposed to severe trauma and $95 \%$ of adolescents from Democratic Republic of Congo exposed to PTSD. This indicates the severity of trauma amongst adolescents leading the researcher to search on adolescent trauma in Uganda specifically in Entebbe Municipality in Uganda.

In Uganda, Mandrup, L. \& Ask, Elklit, quoted, studies carried out focused exclusively on former child soldiers and internally displaced people, Lamaro P Onyut et al., [11]. The study of former Ugandan and Congolese child soldiers report that over $35 \%$ of their sampled size, had moderate to very severe PTSD symptoms Nalugya-Sserunjogi et al., [12], further quotes from her study the prevalence estimate of depression (which is a PTSD) issue at $21 \%$ high and further explained that this high estimate is likely to impair the adolescents functioning.

Mutto, M., [13], highlights that injuries are among the causes of aftermath trauma in adolescents, citing examples such as domestic or home injuries, road accidents, school and hospital-related injuries. Mutto further quotes violent injuries among youth at $7.3 \%$ with fatality case rate of $4 \%$.

In Uganda, Yasmin et al., [14], in their psychological well-being research, revealed that there is a need to focus on adolescent wellness in developing countries.

\section{Materials and Methods}

\section{Research Design}

The researcher used exploratory case study design Gesa [15], by exploring the nature of the study and for in-depth analysis. Under exploratory case study design, mixed methods of qualitative and quantitative research approach was used to collect data. The study used triangulation technique involving collecting and analyzing data by mixing different methods Amin, [16]. Triangulation is based on the assumption that any bias inherent in particular data sources, investigators and methods would be neutralized when used together with other data sources, investigators and methods. The triangular methods involved both use of qualitative and quantitative approaches in the study of nature of trauma and psychosocial wellbeing of adolescents and the relationships between the two.

\section{Population of the Study}

The total population of the study constituted 215 adolescents (Students) between the age of 12-18 years from Entebbe municipality in Wakiso district in Uganda and target population was 110 from senior 1,2 and 3; and Counselors/ social workers, teachers and parents between the ages of 25-45 years. The target population was 110 .

\section{Sample Size}

The study used Morgan and Krejcie (1970) as quoted by Amin for selecting the sample size basing on the number of respondents involved in research. Given that the target population of the known population was 110 , the following formula was used to determine the sample size.

$$
\begin{aligned}
& \mathrm{S}=\mathrm{NP}(\mathrm{P})(1-\mathrm{P}) / \mathrm{NP}-1(\mathrm{~B} / \mathrm{C})^{2}+\mathrm{P}(1-\mathrm{P}) \\
& \text { Interpretation: } \\
& \mathrm{S}=\text { Sample size } \\
& \mathrm{NP}=\text { Population } \\
& \mathrm{P}=\text { Population proportion magnitude yielding to the } \\
& \text { maximum sample size } 50 \%=0.5 \\
& \mathrm{~B}=\text { Sampling error } 5 \%=0.5 \\
& \mathrm{C}=\text { Confidence level }=1.960 \\
& \text { Therefore; } \mathrm{P}=0.05,(\mathrm{P})(1-\mathrm{P})=0.25 \\
& (\mathrm{~B} / \mathrm{C})^{2}=0.00065077051 \\
& \mathrm{~S}=\frac{60(0.25)}{N-1(0.00065077051)+0.25} \\
& \mathrm{~S}=\frac{110 \times 0.25=27.5}{109 x 0.000650770051=0.07093398559} \\
& 0.07093398559+0.25=0.32093398559 \\
& \mathrm{~S}=\frac{27.5}{0.32093398559} \\
& \mathrm{~S}=85.68740374891874 \\
& \mathrm{~S}=86 .
\end{aligned}
$$

The selection of the sample 86 respondents was thus based on in this study.

Table 1. Estimated Sample size

\begin{tabular}{|c|c|c|c|c|}
\hline Category & Population & Sample size & Sampling techniques & Instrument used \\
\hline Teachers & 10 & 6 & Purposive & Focus Group Discussion \\
\hline Parents & 15 & 11 & Purposive/ snow ball & Focus Group Discussion \\
\hline Counselor/ Social workers & 5 & 3 & Purposive & Focus Group Discussion \\
\hline Students & 80 & 66 & $\begin{array}{c}\text { Simple random sampling/ } \\
\text { Purposive sampling }\end{array}$ & Standardized questionnaire \\
\hline Total & 110 & 86 & & \\
\hline
\end{tabular}




\section{Selection Procedure or Techniques}

The study used a sample size of respondents who were selected from the school, health center and community. The study employed purposive or snow ball sampling and simple random sampling. The freedom from human bias and classification error remains one of the biggest advantages simple random sampling offers, as it gives every member of the population an equal probability of being selected. In simple random sampling, only the complete listing of the elements in a population called sampling frame is needed. A simple random sample, being highly representative of a population, also simplifies data interpretation and analysis of results. Purposive sampling was used to identify persons who have some specific knowledge about the topic being investigated.

\section{Data Collection Instrument}

The study used instruments like questionnaires, and focus group discussion.

\section{Questionnaire}

The study used likert scale is an ordinal psychometric measurement of attitudes, beliefs and opinions. The likert scale standardized questionnaire "The child and adolescent trauma screen (CATS)"was administered to adolescent in relation to objective one and two to collect data on the nature of trauma and psychosocial wellbeing.

\section{Focus Group Discussion}

In order to obtain more classified information regarding the study objective three, the study used focus group discussion and this was carried out with the parents, teachers and counselors/ social workers to collect data.

\section{Data Quality Control}

Validity was determined using Content Validity Index (C.V.I). C.V.I=Items rated relevant by both judges divided by the total number of items in the questionnaire as shown hereinafter.

The study adopted existing standardized instrument already measured and published

$$
\begin{aligned}
& \text { Judge 1: } \frac{65}{70} \times 100=93 \% \\
& \text { Judge 2: } \frac{64}{70} \times 100=91 \% \\
& \text { Judge 3: } \frac{67}{70} \times 100=96 \% \\
& \frac{93+91+96}{3}=\frac{280}{3}=\frac{93}{100}=0.93 \\
& \text { Content Validity index is } 0.93
\end{aligned}
$$

\section{Reliability}

Reliability measures consistency of instruments by computing the variables using SPSS to find out Cronbach's Alpha coefficient. The result from findings are presented and explained in table 2 below.
Table 2. Cronbach's Alpha coefficient

\begin{tabular}{|c|c|c|}
\hline & Cronbach's Alpha & Number of items \\
\hline Stressful events & 0.505 & 5 \\
\hline Effects of trauma & 0.765 & 7 \\
\hline Psychosocial wellbeing & 0.610 & 5 \\
\hline
\end{tabular}

The results in table above, the Cronbach's Alpha was found to exist in the questionnaire. This indicated that there is a higher level of internal consistency which is above 0.5 .

\section{Data Analysis Procedure and Presentation}

Data analysis procedure involved organization and interpretation of the data generated through editing and coding. The data analysis contained both quantitative and qualitative methods.

Quantitative analysis; quantitatively statistical analysis was used and information was entered and analyzed using Statistical Package for Social Scientists (SPSS) and used to work out percentages and frequencies. Qualitatively the analysis included a critical study at the responses from discussions with the parents, counselors/social workers and teachers.

\section{Results}

Findings were done in relation to study objectives and presented in tables, pie charts and columns. The study objectives were; to investigate the nature of trauma among adolescents in three selected schools in Entebbe Municipality in Uganda; to assess effects of trauma on psychosocial wellbeing of adolescents in three selected schools in Entebbe Municipality in Uganda.

\section{Demographic Information}

\section{Gender of respondents.}

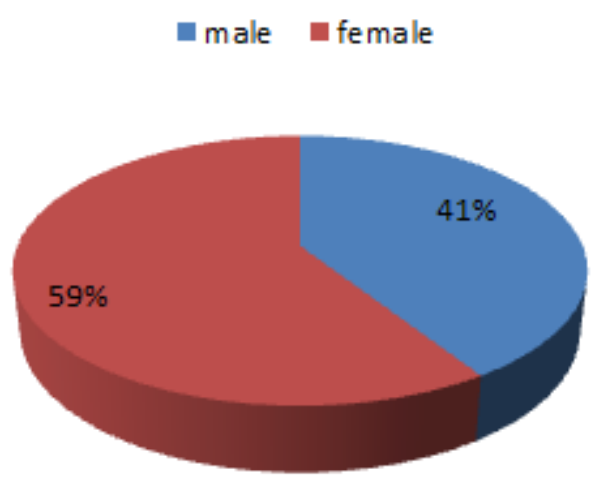

Source: Field data, (2017).

Figure 2. Gender of the respondents (Adolescents):

Basing on the findings in figure 2 above, the gender of 
66 respondents (adolescents), 39 (59\%) of the respondents were females and $27(41 \%)$ of the respondents were male represented in the study. This was because in the selected schools there were more girls than boys. This is further evidenced by Ugandan census statistics of 2014 with $16,935,456$ males as compared to $17,921,357$ females.

Table 3. Age of respondents (Adolescents):

\begin{tabular}{|c|c|c|c|c|}
\hline & \multicolumn{2}{|c|}{ Frequency } & Total \\
\hline Years & Girls & Boys & \\
\hline $12-15$ years & 16 & & 9 & 25 \\
\hline $16-18$ years & 23 & & 18 & 41 \\
\hline Total & 39 & & 27 & 66 \\
\hline & & & & \\
\hline
\end{tabular}

Source: Field data, (2017).

Basing on the findings in table 3 above, there are more girls of 16-18 years totaling to 23 and girls between 12-15 years totaling to 16 years as compared to boys between 16-18 totaling to 18 and those aged $12-15$ years totaling to 9 respectively. The purposively selected classes were those in form, one, two and three classes.

\section{Nature of Trauma among adolescents}

A self-administered questionnaire was conducted and results were measured from emotional, physical and sexual components. Emotional trauma among adolescents results are presented in table 4 below:

Table 4. Someone close to you dying suddenly or violently, watching them die or treating them for a long time.

\begin{tabular}{|c|c|c|c|c|c|}
\hline \multicolumn{2}{|c|}{} & Frequency & Percent & $\begin{array}{c}\text { Valid } \\
\text { Percent }\end{array}$ & $\begin{array}{c}\text { Cumulative } \\
\text { Percent }\end{array}$ \\
\hline \multirow{3}{*}{ Valid } & yes & 30 & 45.5 & 45.5 & 45.5 \\
\cline { 2 - 6 } & no & 36 & 54.5 & 54.5 & 100.0 \\
\cline { 2 - 6 } & Total & 66 & 100.0 & 100.0 & \\
\hline
\end{tabular}

Source: field data (2017)

According to the findings in the table 4 above, $45 \%$ of the adolescents were emotionally traumatized by the death of close relatives. This indicates a need for intensive grief counseling to avoid complicated grief among adolescents which ultimately leads to psychosocial problems.

\section{Physical Abuse}

Franziska, et al., [17] defined physical abuse as a non-accidental use of force that results in bodily injury, pain or impairment.

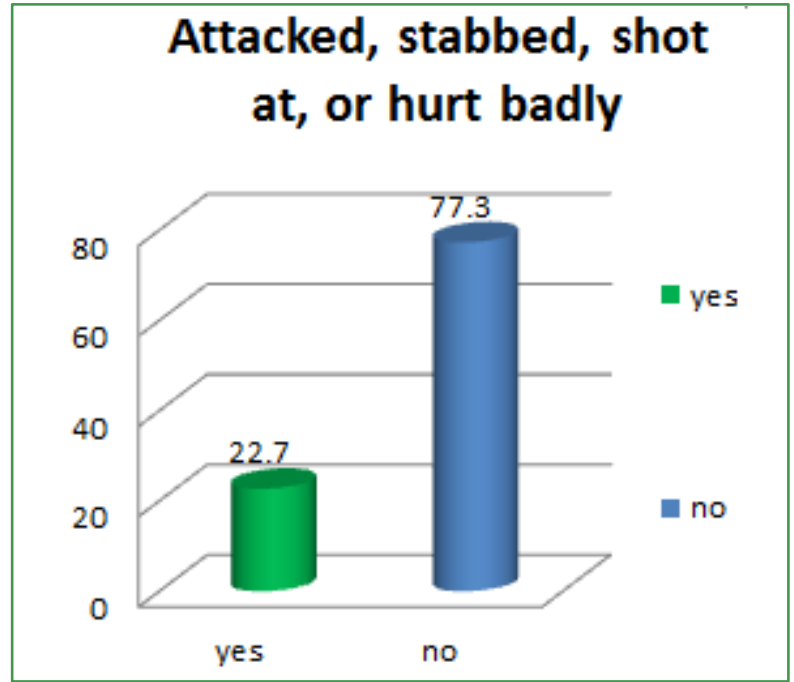

Source: field data (2017)

Figure 3. Attacked, stabbed, shot at or hurt badly

According to the data findings in figure 3 above, when respondents were presented with statement attacked, stabbed, shot at, hurt badly or killed, $\mathrm{n}=66,51(73 \%)$ said no, $15(27 \%)$ said yes. This indicates that respondents not attacked, stabbed, shot at, hurt badly or killed to be $73 \%$.

Adolescents from this study were less traumatized by personally being attached, stabbed or short at with $22.7 \%$. The study further revealed that out of who responded "yes" there were more males at $66 \%$ at as compared to females $54 \%$.

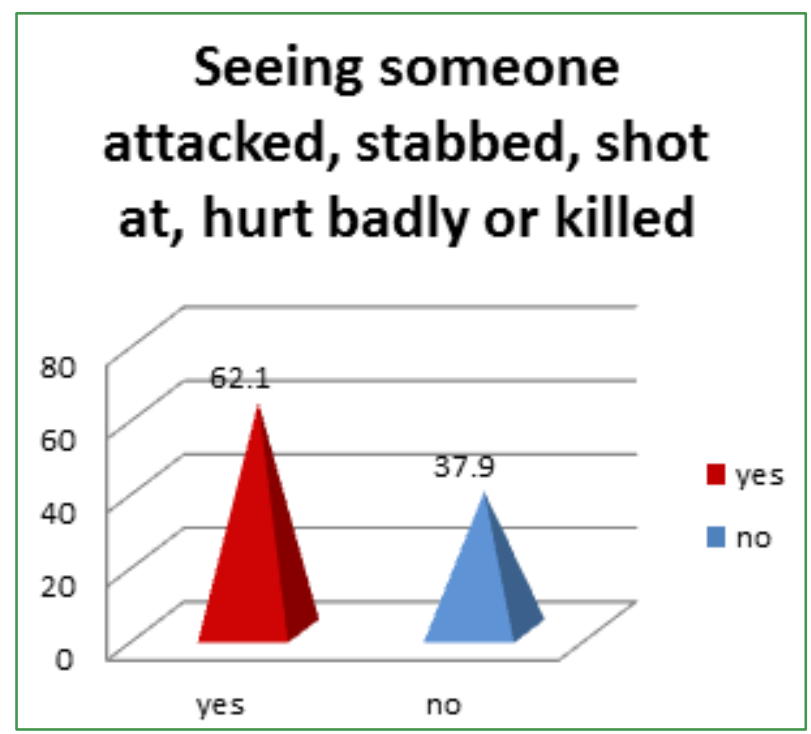

Source: field data (2017)

Figure 4. Seeing someone attacked, stabbed, shot at, hurt badly or killed

According to the data findings in figure 4 above, when respondents were presented with statement seeing someone attacked, stabbed, shot at, hurt badly or killed, $\mathrm{n}=66$, $41(62 \%)$ said "yes", 25(38\%) said "no". This indicates that respondents seeing someone attacked, stabbed, shot at, hurt badly or killed with $62.1 \%$. This raises concern on the 
nature of adolescent psychosocial wellbeing.

\section{Sexual Abuse}

Table 5. Someone forcing or pressing for sex

\begin{tabular}{|c|c|c|c|c|c|}
\hline \multicolumn{2}{|c|}{} & Frequency & Percent & $\begin{array}{c}\text { Valid } \\
\text { Percent }\end{array}$ & $\begin{array}{c}\text { Cumulative } \\
\text { Percent }\end{array}$ \\
\hline \multirow{3}{*}{ Valid } & yes & 10 & 15.2 & 15.2 & 15.2 \\
\cline { 2 - 6 } & no & 56 & 84.8 & 84.8 & 100.0 \\
\cline { 2 - 6 } & Total & 66 & 100.0 & 100.0 & \\
\hline \multicolumn{6}{|c|}{ Source: field data (2017) } \\
\hline
\end{tabular}

Basing on table 5 above, when the respondents were presented with the statement someone forcing or pressing sex. This finding reveals that $15 \%$ have been sexually traumatized. Sexual trauma easily results into sexually induced-psychosis and phobic behaviors manifested in being overly anxious with opposite sex who may be presumed to be a potential abuser. This study further revealed that out of the frequency of $10 \%$ who are sexually abused $7(70 \%)$ were females and $3(30 \%)$ were males.

\section{someone older touching your private parts when they should not}

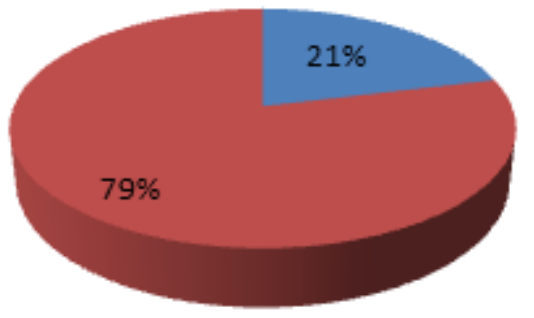

-yes

no

Source: Field data (2017)

Figure 5. Someone older touching your private parts when they should not

This figure 5 reveals that $21 \%$ of the adolescents were touched inappropriately on their sexual private parts by some older persons. The study revealed further that out of these $58.8 \%$ was females and $46.1 \%$ were males. This indicates that the level of sexual exploitation and abuse is on high rate among the adolescents in Entebbe-Uganda.

\section{Other Stressful or Scary Events}

These have been summarized within the two broad domains of domestic violence related events and fear of failing exams or repeating a class.

These have been summarized within the two broad domains of domestic violence precipitated by scary events like a belief in witchcraft with $n=24(36 \%)$ being stressed by poverty with $18(27 \%)$, their parents failing to pay rent, illness of the family member with $4(6 \%)$, and Coming late at night by a family member with $3(5 \%)$ and the second domain being fear of failing exams or repeating a class with $17(26 \%)$. This finding reveals that poverty is highest source of trauma followed by fear of failure especially failure to succeed in their studies among adolescents in Entebbe-Uganda.

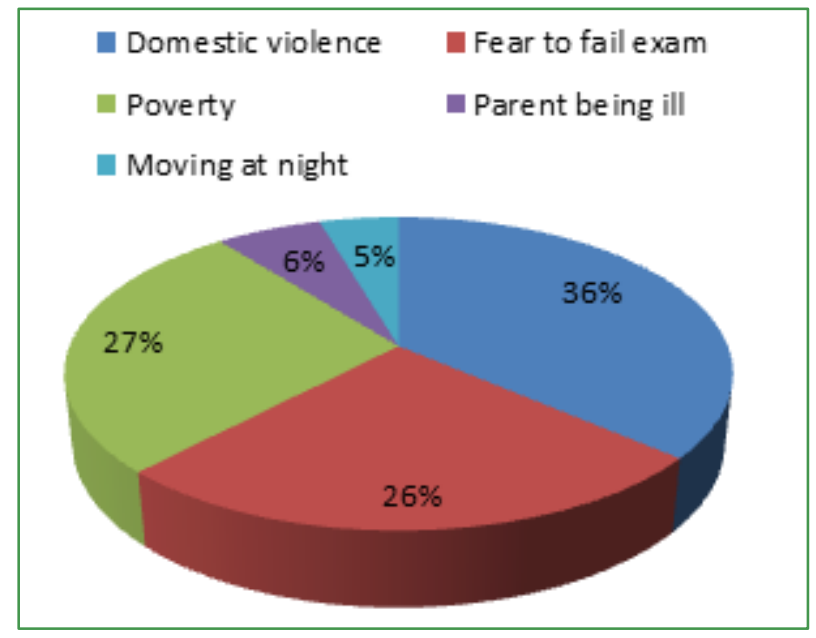

Source: Field data, (2017).

Figure 6. Other stressful or scary events obtained from the findings affecting the wellbeing of adolescents.

\section{Effects of Trauma on Psychosocial wellness of adolescents in Entebbe-Uganda}

This section forms the results from objective two of this study. This objective has obtained the results from the questionnaire that looked at the three major areas of psychosocial wellness of adolescents and these are Impairment in Attachment, Difficulties in Academic Functioning and Somatic complaints precipitated by past traumatic events.

\section{Impairment in Attachment}

Table 6. Bad feelings (afraid, angry, guilty, and ashamed) a lot of the time with others.

\begin{tabular}{|c|c|c|c|c|c|}
\hline \multicolumn{2}{|c|}{} & Frequency & Percent & $\begin{array}{c}\text { Valid } \\
\text { Percent }\end{array}$ & $\begin{array}{c}\text { Cumulative } \\
\text { Percent }\end{array}$ \\
\hline \multirow{7}{*}{ Valid } & $\begin{array}{c}\text { never } \\
\text { once in a } \\
\text { while }\end{array}$ & 16 & 24.2 & 24.2 & 24.2 \\
\cline { 2 - 6 } & half the time & 12 & 18.2 & 18.2 & 69.7 \\
\cline { 2 - 6 } & $\begin{array}{c}\text { almost } \\
\text { always }\end{array}$ & 20 & 30.3 & 30.3 & 100.0 \\
\cline { 2 - 6 } & Total & 66 & 100.0 & 100.0 & \\
\hline
\end{tabular}

Source: field data, (2017)

Basing on the table 6 above there are a lot of attachment related issues in issues of bad feelings with the cumulative frequency of 50(75.7\%) as indicated with those who had at least experienced some guilt. This indicates the depth of emotional harm as a result of impaired attachment resulting from past traumatic events. This study further revealed that 
out of those experiencing guilt $19(38 \%)$ were males and $31(62 \%)$ were females.

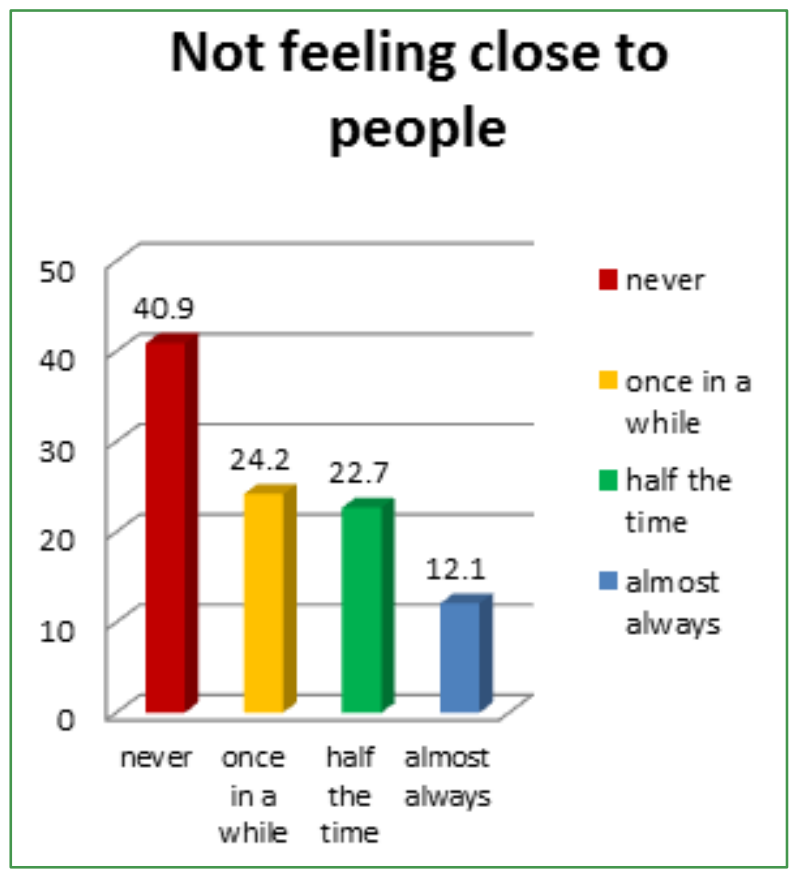

Source: Field data, 2017

Figure 7. Not feeling close to people.

Basing on the figure 7 above when respondents were presented with the statement not feeling close to people, cumulative $59 \%$ of the adolescents do not feel close to other people. This further reveals how traumatic event affects the interpersonal skills and association. This can be manifested in experience of social withdrawal, loneliness and isolation symptoms and thus affecting the psychosocial wellbeing of adolescents. This study further revealed of these $32(54.2 \%)$ were females and $27(44.8 \%)$ were males.

\section{Feeling mad.Having fits of anger and taking it out on others}

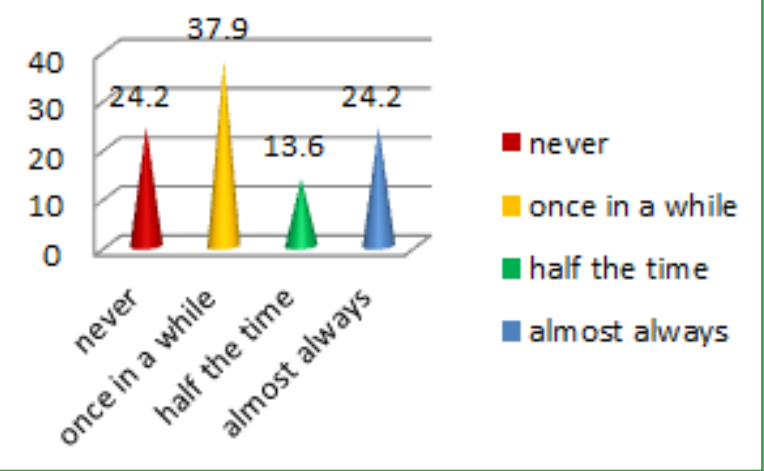

Source: Field data, 2017.

Figure 8. Feeling mad. Having fits of anger and taking it out on others
Basing on the figure 8 above when respondents were presented with the statement feeling anger and taking it on others revealed that $75.8 \%$ were angered about others. This study further revealed that out of these affected by anger there were more males with $66 \%$ and females with $34 \%$.

\section{Difficulties in Academic Functioning}

This looked at two areas of; Lack of enthusiasm manifested in not wanting to do what they were used to do before traumatic events and problems related with paying attention.

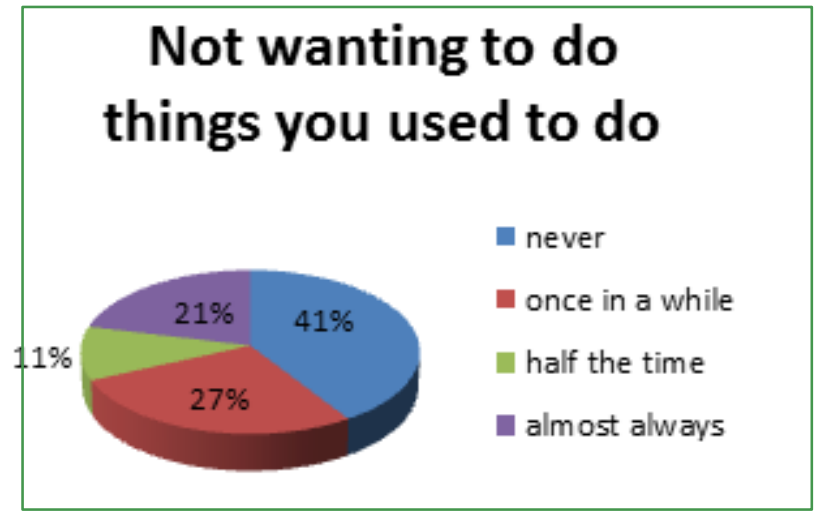

Source: Field data, (2017).

Figure 9. Not wanting to do things you used to do

Basing on the figure 9 above when respondents were presented with the statement not wanting to do things you used to do, the study revealed that $75 \%$ of the adolescents in the area of study had difficulties in connection with enthusiasm to do things that previously they could do to enhance their academic work. This finding further indicated that females were more affected with $63.4 \%$ and males with 36.6 being males.

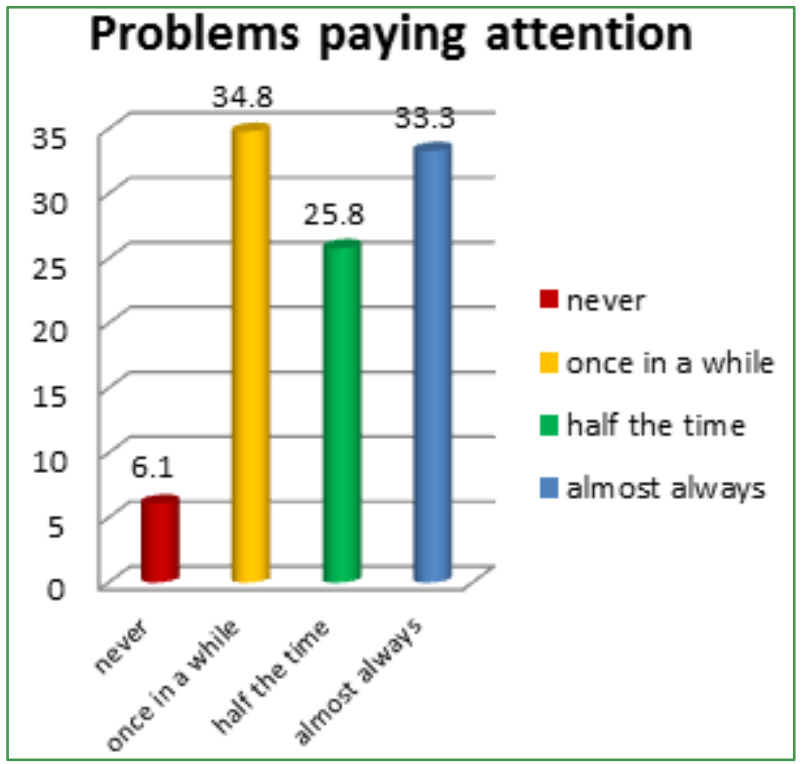

Source: Field data, (2017).

Figure 10. Problem paying attention 
Basing on figure above 10, results indicated that problem paying attention with $93.9 \%$ having experienced periods of problems with attention due to thoughts and the remembrance about past traumatic events that they have gone through. The study asserted that $6.1 \%$ of the respondents said that they had no trouble with paying attention in their academic studies. This study further revealed that $71.3 \%$ females were affected in comparison to $28.7 \%$ males.

\section{Somatic Complaints}

The result of this stud was delivered from the questionnaire based on two elements of; bad feeling about one's body and sleep related problems.

Table 7. Bad feeling about one's body

\begin{tabular}{|c|c|c|c|c|c|}
\hline \multicolumn{2}{|c|}{} & Frequency & Percent & $\begin{array}{c}\text { Valid } \\
\text { Percent }\end{array}$ & $\begin{array}{c}\text { Cumulative } \\
\text { Percent }\end{array}$ \\
\hline \multirow{7}{*}{ Valid } & never & 16 & 24.2 & 24.2 & 24.2 \\
\cline { 2 - 6 } & $\begin{array}{c}\text { once in a } \\
\text { while }\end{array}$ & 21 & 31.8 & 31.8 & 56.1 \\
\cline { 2 - 6 } & $\begin{array}{c}\text { half the } \\
\text { time }\end{array}$ & 17 & 25.8 & 25.8 & 81.8 \\
\cline { 2 - 6 } & $\begin{array}{c}\text { almost } \\
\text { always }\end{array}$ & 12 & 18.2 & 18.2 & 100.0 \\
\cline { 2 - 6 } & Total & 66 & 100.0 & 100.0 & \\
\hline
\end{tabular}

Source: Field data, 2017.

Basing on the table 7 above when respondents were presented with the statement bad feelings about one's body, $75.8 \%$ had an experience of some somatic complications like body aches and twitches. The study pointed out that out of these affected with bad feelings $44 \%$ were males and $56 \%$ of respondents were females.

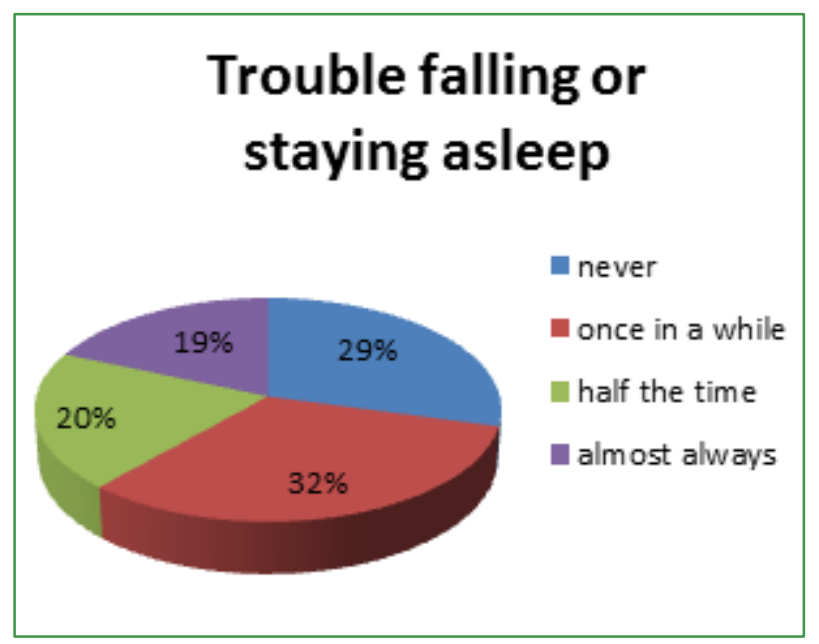

Source: Field data, (2017).

Figure 11. Trouble falling or staying a sleep

Basing on figure 11 above when respondents were presented that $80 \%$ had at least one time experienced some episodes of insomnia associated with traumatic past. This study further revealed that they were more males. This study further revealed that there were more males with $67.6 \%$ with trouble falling asleep and $32.4 \%$ being females.

\section{Perceived Relationship between Trauma and Psychosocial Wellbeing among adolescents}

The researcher obtained results by use of purposive sampling technique using focus group discussion with $\mathrm{n}=20$ discussant include; social workers/counselors, teachers and parents at different intervals. The age of other respondents (Discussants) were $\mathrm{n}=20$ including teachers $\mathrm{n}=6,3$ female between the age of $25-30$ years and 3 male between the age of 30-35 years old, Counselors/Social workers $\mathrm{n}=3,1$ female between the age of 25-30 years and 2 male between the age of 35-40 years old, while the parents were $n=11$, all female and between the age 41-45 years old. Female discussant were $\mathrm{n}=15$ and male discussant were $n=5$. The ages of discussant were between, 25-45. This was meant to bring about qualitative results of the study.

\section{Parents}

Basing to the parents, when presented with a statement, drawing a relationship between trauma and psychosocial wellbeing, parents agreed that there is a relationship between trauma and psychosocial wellbeing of adolescent.

Neglect abuse defined by parents as the failure of a parent, guardian, or other caregiver to provide for a child's basic needs. Neglect may be: Physical (example, failure to provide necessary food or shelter, or lack of appropriate supervision); Medical (example, failure to provide necessary medical or mental health treatment); Educational (example, failure to educate a child or attend to special education needs); Emotional (example, inattention to a child's emotional needs, failure to provide psychological care, or permitting the child to use alcohol or other drugs).

Discussant in the key focus group discussion reported by one of the parents that, "when an adolescent is neglected at home by parents, is sometimes forced to go and leave on streets for survival or collect scrape to earn a living, continued neglect is a form of abuse leading to psychosocial un-wellness in adolescent" (Source: Discussant 2017).

Another discussant in the key focus group discussion said that, "when a husband marries a second wife, adolescents/ youth found in a home are always mistreated to the extent of being denied food, clothes, education and also work as house maids in their father's home. This kind of torture affects the growth and development of psychosocial wellbeing of adolescents", (Discussant, 2017).

When parents were presented with a statement on the factors responsible for psychosocial wellbeing of 
adolescents, Parents through thematic analysis of their responses said that provision of food, shelter, parental involvement and participation in adolescent's life contributes to being confident, good attitude towards school and being morally upright of the adolescents.

When parents were presented with a statement on how do you counsel adolescents when there is a behavioral misconduct? Parent agreed through thematic analysis of their responses that sharing out with other parents for support and guidance, sending them to church leaders to talk to them and also use prayers, and talking to other family members for support are essential for adolescents.

\section{Counselors}

According to counselors/social workers when presented with a statement about drawing a relationship between trauma and psychosocial wellbeing, agreed that there is a correlation between trauma and psychosocial wellbeing of adolescent.

Discussant in the focus group discussion reported that, with an example; "an adolescent born with HIV and living with the virus is not the problem but staying with an abusive guardian, his psychosocial wellbeing is affected and develops antisocial behavior conduct leading to un-wellness" (Discussant, 2017).

When presented with a statement on which techniques do counselors/social worker counselor use on adolescents with psychosocial problems, thematic analysis revealed that Techniques such as peer support, testimony giving, play therapy, sports, family involvement in counseling, training life skills and coping skills and making referrals are essential for adolescents.

When presented with the statement on the factors responsible for psychosocial wellbeing, counselors/ social workers listed good family background, good and enabling environment around the adolescent, level of exposure, good nutrition and access to health services.

A discussant in focus group discussion reported that, "adolescents cope up easily with sports. Sports support the whole body system in management of stress. He continued to say that, sports is part of relaxation exercise and fleshes the mind", Discussant, (2017). Another discussant reported that, "they mostly deal with adolescent living with HIV/AIDS" Discussant, (2017).

\section{Teachers}

Basing on teachers, when presented with a statement on drawing a relationship with trauma and psychosocial wellbeing, the study revealed that Neglect and physical abuse affects psychosocial wellbeing of adolescents. One of the respondents said that, "repeated neglect and physically abused adolescent shows tendencies of absenteeism at school, less interest in learning this affecting his academic performance or intellectual wellbeing".

Using Focus Group Discussion, discussants summed up that, the causes of trauma faced by adolescents are defilement, rape, neglect from parents, and adolescent living with HIV (stigma). Thematic analysis on psychosocial support revealed that the adolescents special attention, care and love; listening, giving positive affirmation such as "you can make it if you don't give up". Two discussants commented that, they find it hard to teach HIV in a class where there is an adolescent living positive. This is because teachers think that, is re-traumatizing the adolescent or an adolescent may think the teacher knows his or her status and that is why is teaching that topic" Discussant, (2017).

On factors responsible on psychosocial wellbeing of adolescent thematic analysis from focus group discussions showed that; having teacher- learner relationship, parental love and care, counseling, understanding, listening and appreciating the adolescents, and good nutrition to be essential for adolescents psychosocial wellness.

\section{Discussion of Findings}

\section{Nature of Trauma among Adolescents in Entebbe Municipality in Uganda}

\section{Emotional Abuse}

Results indicated that other stressful or scary events, $24(36 \%)$ indicated being stressed by domestic violence in their homes, $18(27 \%)$ indicated being stressed by poverty. Most of the respondents mentioned of being thrown out of houses because of their parents failing to pay rent, 17(26\%) indicated having fear of failing exams or repeating a class, $4(6 \%)$ also indicated their parents being ill, and 3(5\%) is scared of moving at night. The findings are in agreement with (Finkelhor, Ormrod, \&Turner, [18] that adolescents are exposed to multiple traumatic events and often develop more severe mental and physical difficulties. Roberta A. Hibbard et al., [19] points out that $20 \%$ out of 3998 adolescents involved in a study, reported some problem behaviors and emotions (including trouble sleeping, difficult with anger) were common among all adolescents and some were strongly associated with a history of abuse. Adolescent experiencing emotional abuses as a result of multiple traumatic events are living with pain even more painful than physical abuse because there are no outward or physical signs of it. In agreement in the study of Latiffah Abdul et al., [20] who argued that psychosocial problems include emotional problems (e.g. anxiety, depression and stress) and behavioural problems (for example educational difficulties, conduct disorders, hyperactivity substance abuse) affect adolescents. Latiffah Abdul et al., further argued that the psychosocial problems are not easy to be 
detected by the parents or teachers, they are easily neglected. The researcher is in agreement with the finding Latiffah et al., because of the emphasis put on emotional abuse which is not seen and neglected. The researcher is in agreement with literature review argued by LR Anuradha et al., in their study that mental health is associated with feeling happy and positive about self and enjoying life; healthy relationships with family and friends; participation in physical activity and eating a healthy diet; the ability to relax and to get a goodnight sleep; and community participation and belonging.

\section{Physical Abuse}

In the current study, the prevalence of physical abuse was very high. Adolescents attacked, stabbed, shot at, hurt badly or killed, were $15(27 \%)$ and those affected by domestic violence caused by parents abusing substance were $24(36 \%)$. The findings are in agreement with Yohannes et al., [21] argued that about 25-50\% adolescents around the world suffer from physical abuse. All over the world children and adolescents are subjected to violence as a punishment by family members or other adults including school teachers and other staff. Yohannes et al., continued to argue that, those abused by their biological parents are about (51\% and 54\%, respectively), while those physically abused by non-biological parents or parents' partners, or by other, perpetrators like teachers are much more likely to be abused by males ( $74 \%$ or more by males versus $26 \%$ or less by females). This affects the physical wellbeing of adolescents in terms of physical activity, and failure to maintain a healthy diet and becoming in tune with how the body responds to various events, stress, and feelings by monitoring internal and external physical signs.

The researcher is in agreement with the findings and Yohannes et al., because of the emphasis put on physical abuse.

While on other hand adolescent who did experience physical abuse were $51(73 \%)$ and if not affected by other stressful events are most likely to have a positive psychosocial wellbeing. With optimism about good health the researcher is in agreement with the findings and Leslie et al., [22] suggesting that seeking medical care when appropriate, and taking action to prevent and avoid harmful behaviors such as tobacco use and excess alcohol consumption and detect illnesses.

\section{Sexual Abuse}

World Health Organization defined Sexual abuse or violence as any sexual act, attempt to obtain a sexual act, unwanted sexual comments or advances, or acts to traffic or otherwise directed, against a person's sexuality using coercion by any person regardless of their relationships to the victim, in any setting, including but not limited to home and work. Someone touching adolescent's private parts when shouldn't with $14(21 \%)$ and someone forcing or pressing sex, or when you couldn't say no, with $10(15 \%)$.
This point out that adolescents experience sexual abuses most especially the female adolescents in schools and in the communities where they live. The current study is in agreement with the findings of Morenike et al. [23] study, who quoted that $10 \%$ to $46 \%$ of adolescent girls have experienced coercive sex. Morenike et al. explained that adolescents worldwide often face tremendous sexual violence and a growing problem and a leading reproductive health concern. With the high prevalence of sexual violence ranges between 15 and $40 \%$ in sub-Saharan Africa, with studies showing rates of sexual coercion and abuse among female adolescents in Nigeria between 11 and 55\%. In 2008, Uganda reported $11.8 \%$ of adolescent girls are affected by cross-generational sex and transitional sexual relations (David Walker et. al., [24]. Still in Uganda, Adolescent Girls Vulnerability Index Report [25] presented a national average of $12.7 \%$ for sexually active girls who have had cross-generational sex. This increases the risk to be sexually abused. Also this increases the risks of contracting HIV- virus and other Sexually Transmitted Diseases, Early childhood marriages, pregnancy crisis, Domestic violence, school dropout, and abortion among others. The implications of these social problems are the mental disorder such as sadness, distress, depression, and death if there is no proper management of mental illness. Less is done to provide psychosocial support after abuse and have fair grounds to be heard under courts of law. The researcher is in agreement with the finding of Morenike et al., and Uganda, Adolescent Girls Vulnerability Index Report because of the emphasis put on sexual abuse.

\section{Effects of trauma among adolescents}

\section{Impairment in Attachment}

Adolescent experiencing bad feelings (afraid, angry, guilty, ashamed) a lot of the time, with $\mathrm{n}=20(30 \%)$ almost always and $12(18 \%)$ half the time is in relation with the high and low score have impaired attachment. In agreement with Cook et al., [43] argues that absence of attachment result in to inappropriate and intrusive closeness, neglect or indifference, and abusive experiences. This leads adolescents not feeling close to people almost always with $8(8 \%)$. This affecting adolescent's social wellness with poor social interaction skills, poor problem solving skills, and inappropriate behavioral conduct.

Having fits of anger and taking it out on others $\mathrm{n}=25(38 \%)$ said once in a while and $9(14 \%)$ said half the time. This showed that respondents are faced with impairment in attachment and this affects adolescent entire social wellbeing.

Adolescents are traumatized with feeling of witnessing someone attacked, stabbed, shot at, hurt badly or killed with 41(62\%) affecting adolescent girls more than adolescent boys. This can be better defined as influence of gender and abuse type on emotional and behavioral risks. The researcher is in agreement with the findings of Cook et 
al., and [26] Bowlby, [27] that the relevance of attachment as a key meaning in development and impaired attachment affects their psychosocial wellbeing. Therefore care givers, peers, psychologist; counselors are needed for support to develop better functioning skills. In summary, traumatized adolescents are affected in all dimensions of life; physically, emotionally, socially, environmentally, intellectually and spiritually.

\section{Difficulties in Academic Functioning}

Adolescents not wanting to do things they used to, $7(11 \%)$ said half the time fail to do homework, class assignments and absenteeism from school. Other Studies have found an association between exposure to abuse and poor academic performance (Crozier \& Barth) [28].

\section{Somatic Complaints}

Somatic complaints are those that have no medical explanation. These includes; gastro-intestinal problems, constipation, heartburn, nausea, vomiting, colitis, migraines, headaches, backaches and skin disorder. These problems although real to the sufferer, may be brought on by stress or emotional factors.

Adolescents not being able to have good or happy feeling, with $21(32 \%)$ once in a while suffer from somatic complaints. The researcher is in agreement with Tidsskr et al., [48] who argued that, it has been suggested that neurobiological changes, increased physiological arousal, and poorer health behaviour in the aftermath of trauma paves the way for somatization. Tidsskret et al., [29] argued that among 15 -year-olds, $18 \%$ reported at least one daily psychological complaint and $14 \%$ reported at least one daily somatic complaint. The study indicates a problem among adolescent in Entebbe Municipality-Uganda which needs to be addressed because it is still reflected in the lowest percentage as $18 \%$ adolescents faced with somatic complaints almost always and not being able to have good or happy feeling.

Adolescents not being able to have good or happy feeling also have trouble falling or staying a sleep with $21(32 \%)$ mentioned once in a while and (18\%) said almost always and this findings are in line with Roberta A. Hibbard et al., [30] who stated that $20 \%$ of adolescents reported some problem with sleep to be common and were strongly associated with a history of abuse. The researcher is in agreement with Roberta et al., because of the emphasis put on somatic complaints. The researcher in agreement with Leslie et al., who indicated that, when all dimensions of life are affected (physical, social, intellectual, spiritual and environmental), adolescents experience mental disorders with negative symptoms of psychosocial wellbeing such as low esteem, poor attitudes and beliefs toward self and life, un awareness and unconstructive handling of feelings, poor relationships and management and un realistic assessment of one's limitations and a developmental focus.

The results and discussions of this study on how trauma affects psychosocial wellness of adolescents has influenced the initiation of the psychosocial treatment model that can be employed among the adolescents as presented in figure 12. It is has been piloted and results obtained reveal outstanding effectiveness in the management of trauma and in the promotion of psychosocial wellness of adolescents. 


\section{Proposed Adolescent Trauma Interventions Model (ATIM)}

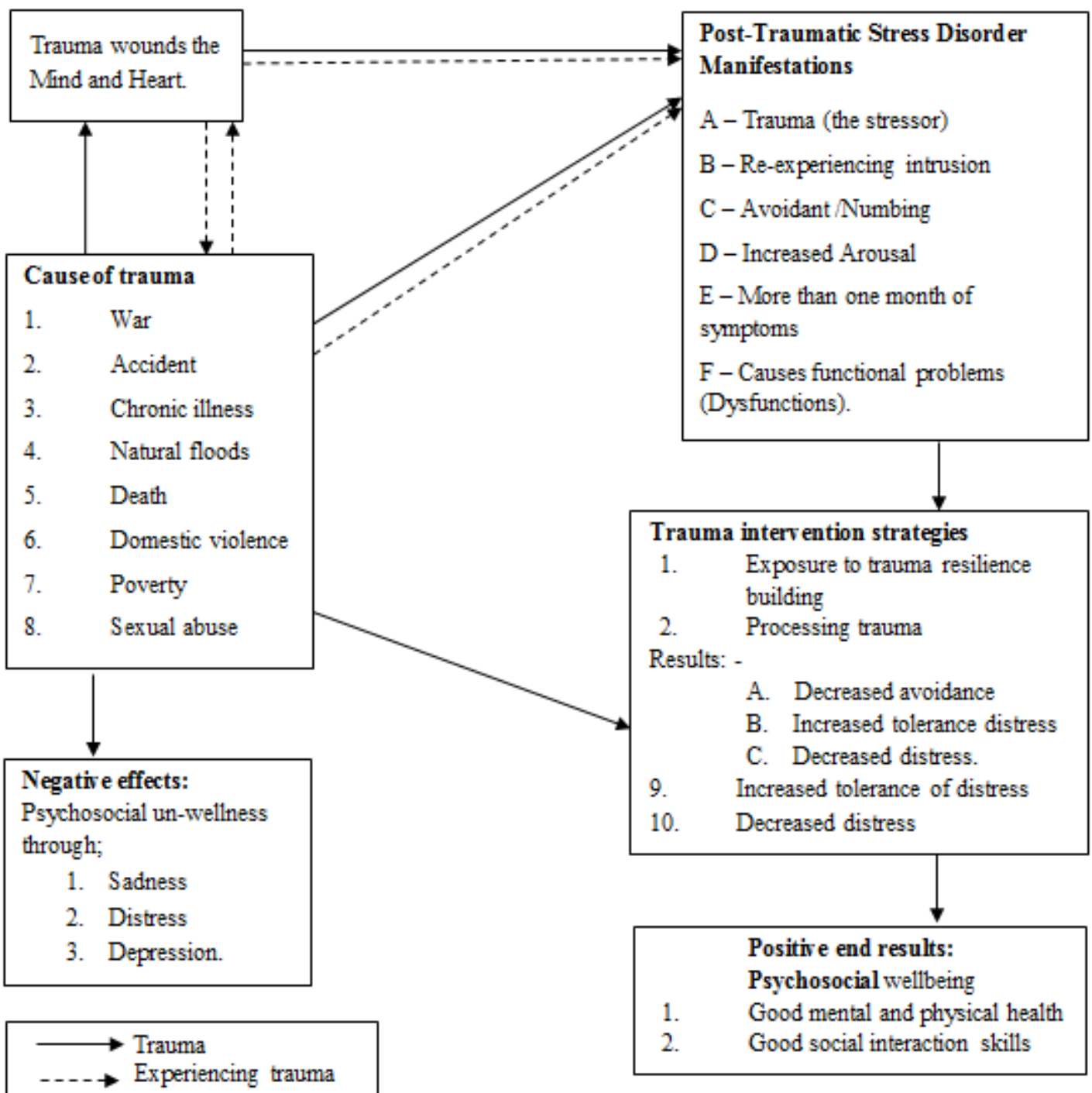

Source: Researcher, 2017.

Figure 12. Adolescent Trauma Interventions Model (ATIM).

From the figure 12 above, Trauma means the psychological wound of the mind and heart. Trauma can be caused by accidents, war, natural hazards, Sexual abuse, poverty, lose, among others. When adolescents are exposed or witnesses overwhelming stressful events, re-experiencing the terrible event with episodes of thought intrusion, avoidance /numbing, increased arousal, happens more than one month, these symptoms re-wounds the mind or the heart and leads to Post Traumatic Stress Disorders leading to adolescents functional impairment. Re-experiencing also causes stress disorders in adolescents. In continuation, to help to mitigate and determine whether an experience becomes traumatic, one must include the adolescent's level of functioning before the traumatic events. Therefore, trauma affects each adolescent differently, some get through the stages of trauma and into recovery fairly fast, experiencing minor upset and difficulties along the way and might not need trauma focused therapies. Whilst other adolescent get stuck along the way and find it difficult if not impossible to move forward with their life, and will need trauma focused therapist to support adolescents build resilience and coping skills for better psychosocial wellbeing through exposure technique, emotional processing, resulting in to decreased avoidance, increased tolerance of distress and decreased distress. This process ultimately leads to psychosocial wellbeing that can be manifested in good mental and physical health and good social interaction skills.

\section{Conclusions}

\section{Causes of trauma among adolescents}

The study concluded that adolescent trauma is caused by 
multiple several factors including Physical causes with more males at $66 \%$, as compared to females $54 \%$, Sexually related causes with $7(70 \%)$ were females and $3(30 \%)$ were males, Being touched indecently at $58.8 \%$ was females and $46.1 \%$ were males, trauma related with poverty with highest source of trauma at $27 \%$ followed by fear of failure especially failure to succeed in their studies $26 \%$. There is a need for multiple psychosocial interventions for adolescents in form of talk and expressive therapies. Studies on trauma argue that some adolescents do experience symptom relief after talking about trauma, while others respond with an exacerbation of symptoms Kestler SA, LoBiondo-Wood G. [31]. As a result, counselors are responsible for managing the intensity of exposure to traumatic materials during the counseling. In a nut shell, different forms of therapies need to complement each other for greater efficacy and effectiveness in psychotherapy leading to psychosocial wellbeing of adolescent in Uganda.

\section{Effects of trauma among adolescents psychosocial wellbeing}

The study further concluded that Effects of trauma among adolescents psychosocial wellbeing were evidenced in Guilt feelings less intensity at 19(38\%) for males and high intensity with $31(62 \%)$ for females, Closeness to others females scored highly with $32(54.2 \%)$ and $27(44.8 \%)$ for males while anger males scored high with $66 \%$ and females with $34 \%$ respectively. The respondents on difficulties in academic performance indicated $63.4 \%$ females and males with $36.6 \%$ being males and on Problems paying attention revealed that $71.3 \%$ females were affected in comparison to $28.7 \%$ males. The study further revealed that on Somatic problems manifested through bad feelings about one's body $44 \%$ were males and $56 \%$ of respondents were females and on sleep related problems there were more males with $67.6 \%$ with trouble falling asleep and $32.4 \%$ being females. This study thus concludes that more adolescent females need psychotherapeutic attention in Uganda and this is in line with what Stevens, Murphy, and McKnight [32] reported their study that there more traumatic stress symptoms among females and thus being at more risk that than male adolescents and in need of more psychosocial intervention strategies.

\section{REFERENCES}

[1] World Health Organization. (2007). Helping youth overcome mental health problems. Geneva: World Health Organization.

[2] Kieling, C., Baker, H., Belfer, M., Conti, G., Ertem, I., Omigbodum, O., Rohde, L.A., Ulkuer, N. \&Rahman, A.
(2011). Child and Adolescent Mental Health Worldwide: Evidence for action, Lancet 378 (9801):1515-1525.

[3] LR Anuradha., Yagnik, V.S. (2012). Improving Positive Mental Wellbeing among Adolescents; Current need. DELHI Psychiatry Journal Vol.15. No 1. Department of Clinical Psychology, IHBAS, Delhi.

[4] Kim, T.M., \&Taub, J. (2008). Trauma and PTSD among Adolescents with Severe Emotional Disorders Involved in Multiple Service Systems. http://ps.psychiatryonline.org/do i/full/10.1176/ps.2008.59.6.627.

[5] Hawkins, S., Radcliffe, J. (2006). Current measures of PTSD for children and adolescents. J Pediatr Psychol.; $31: 420-430)$.

[6] Vittoria, A. (2012). European Journal of Psychotraumatol. 3: 10.3402/ejpt.v3i0.18968.

[7] Dhara, T. (2014). Trauma and Violence Exposure among Asian American and Pacific Islander children: A product of the Asian American Psychological Association leadership Fellows Program. www.aapaonline.org.

[8] Melissa, A.S., Jamie D.A., Stacy, G., Mark, S., Rachael, P., Kimberly, H., Angie, K., David, M.B., Phil, M. (2014). Trauma in Sub-Saharan Africa: Review of Cost, Estimation Methods, and Interventions. Humanitarian Disaster Institute, Wheaton College, United States.

[9] Sida. (2005). Children in Africa with experiences of massive trauma. (Department for Research Cooperation). doi: $10.1186 / \mathrm{s} 12889-015-1780-8$

[10] Mandrup, L. \&Elklit, A. (2014). Victimization and PTSD in Ugandan Youth: Open Journal of Epidemiology. Scientific Research. Publishing Inc.

[11] Lamaro, P.O., Frank, N., Verena, E., Elisabeth, S., Michael, O. \& Thomas, E. (2009). Trauma, poverty and mental health among Somali and Rwandese refugees living in an African refugee settlement - an epidemiological study, Conflict and Health 20093:6; licensee BioMed Central Ltd. 2009.

[12] Nalugya, J.S., ZariRukundo,G., Emilio, O., Kiwuwa, S.M., Seggane, M., and Nakimuli, E.M. (2003). Prevalence and factors associated with depression symptoms among school-going adolescents in Central Uganda. https://capmh.biomedcentral.com/articles/10.1186/s13034-0 16-0133-4

[13] Mutto, M. (2011). Injuries among Children and Young Adults in Uganda: Epidemiology and Prevention. https://openarchive.ki.se/xmlui/handle/10616/40536

[14] Yasmin, K., Muhammed, T., \& Keramat, N. (2015). Psychological Well-being (PWB) of school Adolescents aged 12-18yr, its Correlation with general Levels of Physical Activity (PA) and Socio-Demographic Factors InGilgit, Pakistan. Iranian Journal of Public health.

[15] Gesa, A. (2016). Understanding Research and Statistical Methods. New Edition.

[16] Amin, M. E. (2005). Social science research: Concepts, Methodology \& Analysis. Makerere University Printery. P.O. Box 7062, Kampala-Uganda.

[17] Franziska, M., Lucie, D.C., Mark, E.B., HeidiLoening-Voysey. (2016). Physical, Emotional and 
Sexual Adolescent Abuse Victimization in South Africa: Prevalence, Incidence, Perpetrators and Locations. "Journal of Epidermiology and Community Health. Doi.10.1136/jech-2015-205860.

[18] Finkelhor, D., Ormrod, R. K., \& Turner, H.A. (2007). Re-Victimization Patterns in a National Longitudinal Sample of Children and Youth: Crimes against Children Research Center, University of New Hampshire, 126 Horton Social Science Center, Durham, NH 03824, USA.

[19] Roberta, A. H., Gary, M. I., Donald, P. O. (1990). Behavioral Risk, Emotional Risk, and Child Abuse among Adolescents in a Non-clinical Setting. Volume 86/issue 6.

[20] Latiffah, A., Esra, T., Normala, I., Azrin, S., Shirin, S. (2017). Malaysian Journal of Medicine and Health Sciences (ISSN 1675-8544). Original Article. Psychosocial Problem and its Associated Factors among Adolescents in the Secondary Schools in Pasir Gudang, Johor. ttp://www.medic.upm.edu.my/upload/dokumen/201705031 4440805_MJMHS_Jan_2017__0014_Psychosocial_Proble m.pdf.

[21] Yohannes, S.U., Misgun, S. M. \&Addisu, A.G. (2017). Prevalence and Contributing Factors of Childhood Physical Abuse in Households and at Schools among School Adolescents in Arba Minch Town, Southern Ethiopia. Master of Public Health, Arba Minch University, Arba Minch, Ethiopia.

[22] Leslie, T. F., Keller, C. P., Brian, M., \& Aleck, O. (2011). British Columbia Atlas of Wellness. $2^{\text {nd }}$ ED Http://www.geog.uvic.ca/weelness/wellness 2011. Western Geographical Press, (Book, online)

[23] Morenike, O.F., Morolake, O., Abigail, H., and Brandon, B. (2014). Rape in Nigeria: A Silent Epidemic among Adolescents with Implications for HIV Infection. https://doi.org/10.1371/journal.pone.0155210
[24] David, W., Paola, P., Grace, B., \& Eric, O. (2014). Sexua exploitation of adolescent girls in Uganda. https://resourcecentre.savethechildren.net/sites/default/files/ documents/9274.pdf

[25] Uganda, Adolescent Girls Vulnerability Index Report (2013)

[26] Cook, A., Spinazzola, J., Ford, J., Lanktree, C., Blaustein, M., Sprague, C., van der, K.B. (2005). Complex trauma in children and adolescents. http://www.traumacenter.org/prod ucts/Complex\%20Trauma\%20White\%20Paper.pdf. Psychiatric Annuals, 35, 390-398.

[27] Bowbly, J. (1982). Attachment ( $2^{\text {nd }}$ Edition). New York, NY: Basic Books.

[28] Crozier, J.C., \& Barth, P.P. (2005). Cognitive and Academic Functioning in Maltreated Children. https://www.researchgate.net/publication/273026408_Cog nitive_and_Academic_Functioning_in_Maltreated_Childre n.

[29] Tidsskr, N.L., Aarø LE, Haugland, S., Hetland. J., Torsheim, T., Samdal, O., Wold, B. (2001). Subjective health complaints in adolescence: Dimensional structure and variation across gender and age. DOI: $10.1177 / 140349480203000309$

[30] Roberta, A. H., Gary, M. I., Donald, P. O. (1990). Behavioral Risk, Emotional Risk, and Child Abuse among Adolescents in a Non-clinical Setting. Volume 86/issue 6.

[31] Kestler SA1, LoBiondo-Wood G. (2012). Review of symptom experiences in children and adolescents with cancer. Cancer Nurs. 2012 Mar-Apr; 35(2):E31-49. doi: 10.1097/NCC.0b013e3182207a2a.

[32] Stevens SJ, Murphy BS, McKnight K (2003).Traumatic stress and gender differences in relationship to substance abuse, mental health, physical health, and HIV risk behavior in a sample of adolescents enrolled in drug treatment. Child Maltreat. Feb; 8(1):46-57. 